\begin{tabular}{|c|l|}
\hline Title & Tumor necrosis factor-al pha genetic polymorphism may contribute to progression of bovine leukemia virus infection \\
\hline Author(s) & $\begin{array}{l}\text { Konnai, Satoru; U sui, Tatsufumi; I keda, Manabu; Kohara, Junko; Hirata, Toh-ichi; Okada, Kosuke; Ohashi, Kazuhiko; } \\
\text { Onuma, Misao }\end{array}$ \\
\hline Citation & $\begin{array}{l}\text { Microbes and Infection, 8(8), 2163-2171 } \\
\text { https://doi.org/10.1016/.micinf.2006.04.017 }\end{array}$ \\
\hline Issue Date & 2006-07 \\
\hline Doc URL & http://hdl.handle.net/2115/15426 \\
\hline Type & article (author version) \\
\hline File Information & MI8-8.pdf \\
\hline
\end{tabular}

Instructions for use 
Full Length Article

\section{Tumor Necrosis Factor-Alpha Genetic Polymorphism May Contribute to Progression of Bovine Leukemia Virus-infection}

Satoru Konnai ${ }^{\text {a, }}$, Tatsufumi Usui ${ }^{\text {a }}$, Manabu Ikeda ${ }^{\text {, }}$, Junko Kohara ${ }^{\text {c }}$, Toh-ichi Hirata ${ }^{\text {b }}$ Kosuke Okada $^{\text {b }}$, Kazuhiko Ohashi ${ }^{\text {a }}$, Misao Onuma ${ }^{\text {a }}$

a Department of Disease Control, Graduate School of Veterinary Medicine, Hokkaido University, Sapporo, Hokkaido 060-0818, Japan

${ }^{\mathrm{b}}$ Faculty of Agriculture, Iwate University, Morioka, Iwate 020-8550, Japan

${ }^{\mathrm{c}}$ Hokkaido Animal Research Center, Shintoku, Hokkaido 081-0038, Japan

Running title: Analysis of TNF-a genetic polymorphism and its effect on BLV-disease

$$
\text { progression }
$$

Correspondent footnote: * Department of Disease Control, Graduate School of Veterinary Medicine, Hokkaido University, Sapporo, Hokkaido 060-0818, Japan. Phone: +81-11-706-5215. Fax: +81-11-706-5217. E-mail: konnai@vetmed.hokudai.ac.jp 


\begin{abstract}
In a previous report, we had indicated that in a sheep model, the expression of tumor necrosis factor (TNF)- $\alpha$ was closely associated with disease progression in sheep experimentally infected with bovine leukemia virus (BLV). However, the individual variabilities are observed in these responses in BLV-infected animals. To attempt to identify genetic factors promoting the progression to BLV-induced lymphoma, we endeavored to determine whether there are any polymorphisms in the TNF- $\alpha$ gene among 291 individuals and whether this would affect the level of TNF- $\alpha$ expression and concomitant progression of BLV-induced disease or increase in the provirus load in the carriers. We found that the frequency of the TNF- $\alpha-824 \mathrm{G}$ allele, which has been associated with low transcription activity of the promoter/predicted enhancer region of the bovine TNF- $\alpha$ gene, was higher in individuals with BLV-induced lymphoma than in asymptomatic carrier individuals. In addition, we observed a tendency of increased BLV-provirus load in cattle with TNF- $\alpha-824 \mathrm{G} / \mathrm{G}$ homozygote compared to TNF- $\alpha-824 \mathrm{~A} / \mathrm{A}$ homozygote or TNF- $\alpha-824 \mathrm{~A} / \mathrm{G}$. These data suggest that the observed polymorphism in the promoter region of TNF- $\alpha$ gene could at least in part contribute to the progression of lymphoma in BLV-infection.
\end{abstract}

Key words: BLV; TNF-alpha; Polymorphism; promoter; Disease progression 


\section{Introduction}

The bovine leukemia virus (BLV), which is structurally and functionally related to the human T-lymphotropic virus types (HTLV)-I and II, is the etiological agent of enzootic bovine leukosis (EBL) [1]. Besides the difference in host range, a notable difference between the two viruses is that, infection by BLV is associated with malignancy of $\mathrm{CD}^{+} \mathrm{B}$-cells, whereas HTLV affects $\mathrm{CD} 4^{+} \mathrm{T}$-cells, the majority of which harbor the provirus. Infection by BLV can remain clinically inapparent with the host in an aleukemic state (AL), or it can emerge as persistent lymphocystosis (PL) with non-malignant polyclonal expansion of $\mathrm{CD}^{+} \mathrm{B}$-cell, the majority of which harbor BLV provirus and, more rarely, as malignant B-cell lymphosarcoma in various lymph nodes after a long latent period [2]. Resistance or susceptibility to BLV-induced disease is reportedly determined by several host immune responses [3]. However, the way in which BLV induces the different disease stages during the progression of EBL is still unknown.

Tumor necrosis factor (TNF)- $\alpha$ is of central importance in viral dynamics because, along with other cellular immunity associated cytokines, it is thought to be a protective factor in the progression of various viral infections [4,5]. In our previous reports, we have shown that the expression of TNF- $\alpha$ is closely associated with disease progression in sheep experimentally infected with BLV [6,7]. Interestingly, we observed that the expression of the TNF- $\alpha$ mRNA was significantly up-regulated in BLV infected sheep, resulting in elimination of BLV-infected cells. In contrast, sheep with down-regulated TNF- $\alpha$ mRNA expression showed no elimination of BLV-infected lymphocytes [6]. 
Recently, Muller and co-workers [8] reported that the lack of TNF- $\alpha$ expression resulted in enhanced persistence of BLV-infection in TNF- $\alpha-/-$ mice. These findings suggest an important role played by TNF- $\alpha$ in the elimination of BLV during the early phase of the infection. However, it still remains unclear whether the level of TNF- $\alpha$ expression directly co-relates to the rate of elimination of BLV-infected cells in infected individuals. One hypothesis is that differences in genetic background could elicit different immune responses resulting in either resistance or susceptibility to disease. Nucleotide sequence polymorphisms in genes of some cytokines have been shown to determine the specificity of an individual's immune response and to play roles in conferring resistance or susceptibility to human retroviral infections. Indeed, the association between the provirus load, the susceptibility to disease progression after infection with BLV-related HTLV and the TNF gene polymorphism have been reported [9-12]. However, it remains to be determined whether bovine cytokine genetic polymorphisms, including TNF- $\alpha$, could influence resistance or susceptibility to infectious diseases in the same way like human retroviral infections do. In addition, there is very little information available about cytokine genetic polymorphism and disease progression in domestic animals including cattle. Therefore, it is necessary to investigate the association between the genetic background of domestic animals and their resistance to some infectious diseases. Here, to evaluate the possible role played by TNF- $\alpha$ gene polymorphisms in the propagation of BLV and the modulation of the progression of the ensuing disease, we analyzed TNF- $\alpha$ genes of BLV-infected cattle and show that TNF- $\alpha-824 \mathrm{G}$ is associated with increased progression of BLV-induced 
lymphoma.

\section{Materials and Methods}

\subsection{Characteristics of subjects}

The characteristics of study subjects are summarized in Table 1. A sample group comprising 291 individuals (Japanese black, Holstein-Friesian and First filial of Japanese black/Holstein-Friesian) from thirty-two different dairy farms located in four different areas (Hokkaido, Iwate, Gifu and Niigata) were investigated. It was presumed that the likelihood of the animals being related was remote. Genomic DNA was extracted from whole blood using the Wizard ${ }^{\mathrm{TM}}$ Genomic DNA Purification kit (Promega, Madison, WI) as previously described [13]. Purified genomic DNA concentration was measured by optical density (OD) at $260 \mathrm{~nm}$ and stored at $4^{\circ} \mathrm{C}$ until use. BLV infection was tested by the agar gel immuno-diffusion assay using the BLV env glycoprotein gp51 as antigen, and was further confirmed by real-time PCR, using primer pair BLV-LTR256 (5'-GAG CTC TCT TGC TCC CGA GAC-3') and BLV-LTR453 (5'-GAA ACA AAC GCG GGT GCA AGC CAG-3'), to amplify the BLV long terminal region (LTR) using a LightCycler ${ }^{\mathrm{TM}}$ (Roche Diagnostics, Mannheim, Germany) as described previously [14]. BLV-infected cells were quantified based on viral genome amplification by real-time PCR as described previously [14]. Twenty-five animals with lymphoma were diagnosed clinically, and confirmed by microscopic and histological examinations [15]. Other BLV-positive animals were classified as AL or PL based on the amount of leukocytes and the percentage of 
lymphocytes in their whole blood [13]. Animals were regarded as PL if at least two consecutive leukocyte counts including lymphoid cells were more than $10,000 / \mu 1$.

\subsection{Genotyping of TNF-a gene}

TNF- $\alpha-824 \mathrm{~A} / \mathrm{G},-793 \mathrm{C} / \mathrm{T}$ and $-627 \mathrm{C} / \mathrm{G}$ were genotyped by direct sequence analysis as previously described with minor modifications [16]. DNA fragments of 639bp (from -1044 to -406) upstream of the non-coding region of TNF- $\alpha$ gene [17], were PCR amplified using primer pair TNFA sense (5-CTG GAG AAG TGG GGG TCA-3) and TNFA anti-sense (5-TTA GAA ATG GGA GGG GCT TTA T-3) as described previously [16]. The PCR product was purified with the Gene-clean-III Kit (Q-BIOgene, USA) and sequenced using the CEQ 2000 Dye Terminator Cycle Sequencing method with the Quick Start kit (Beckman Coulter, Inc., Fullerton, CA) according to the manufacture's instructions. The sequence primers used were either TNFA sense or TNFA anti-sense. The sequences obtained for TNF- $\alpha-824 \mathrm{~A} / \mathrm{G}$, $-793 \mathrm{C} / \mathrm{T},-627 \mathrm{C} / \mathrm{G}$ were analyzed using the CEQ 2000 DNA analysis system (Beckman Coulter).

The C-T substitution at position in exon 4 of the TNF- $\alpha$ gene was examined by the PCR-restriction fragment length polymorphism (RFLP) method [18], using primer pair: forward (5'-GGG TGA CTT GCT CTA ACA CTC ATC-3') and reverse (5'-AGG CCT CAC TTC CCT ACA TCC CTA-3'). The PCR products (1233 bp fragments) were subjected to $R s a \mathrm{I}$ (Takara, ostu, Japan) restriction enzyme digestion at $37^{\circ} \mathrm{C}$ for $16 \mathrm{~h}$ fractionated on $1 \%$ agarose gel. The digestion would result in either an intact fragment 
(the $\mathrm{C}$ allele; $R s a I^{*} \mathrm{C}$ ) or one cut into two fragments of 928 and 305 bp (the $\mathrm{T}$ allele; $\left.R s a \mathrm{I}^{*} \mathrm{~T}\right)$. To confirm the identity of the nucleotide, the products were sequenced as described above.

The data were analyzed following the method described Nishimura et al [10]. The statistical significance of the data was determined by the Chi-square method using the Statcel2 software (OMS, Saitama, Japan). To determine the significance of the deviation, Fisher's exact probability test was used when the number of variables expected per cell was less than five. The corrected $\mathrm{p}$ values $(\mathrm{pc})$ were obtained by multiplying the uncorrected $\mathrm{P}$ values $(\mathrm{pu})$ with the number of comparisons; $p<0.05$ was taken as the level of significance.

\subsection{Construction of luciferase fusion plasmids}

The two naturally occurring allelic forms of the TNF- $\alpha$ promoter (TNF- $\alpha-824 \mathrm{~A}$ and TNF- $\alpha-824 \mathrm{G}$ ) were cloned into the luciferase reporter gene construct (Fig. 2A). The TNF- $\alpha$ promoter fragments with $A$ or $G$ at -824 were amplified from genomic DNA isolated from heterozygous cattle using PCR primers (TNFA sense and TNFA anti-sense) containing NheI (Takara) and XhoI (Takara) restriction sites, respectively. The resulting NheI-XhoI fragments were cloned into the NheI and XhoI restriction sites located upstream of the luciferase gene in pGL3-Basic-vector (Promega) to create the TNF- $\alpha-824 \mathrm{~A} / \mathrm{Luc}$ and TNF- $\alpha-824 \mathrm{G} / \mathrm{Luc}$ reporter gene constructs. The plasmids were transformed into Escherichia coli JM109 (Promega). To generate the control reporter gene constructs for monitoring the expression of Tax (a transcriptional activator 
encoded by the X-region of BLV in trans-activation), a 533bp fragment of the BLV-LTR was amplified by PCR with primer pair BLV-LTR1 (5'-TAA TAC GAC TCA CTA TAT AGG G-3') and BLV-LTR533 (5'-GCC GCT CTA GAA CTA GTG GAT CCC-3') and cloned into the pGL3-basic-vector. The propagated recombinant plasmid were confirmed by sequence analysis, digested with NheI and XhoI and transfected into JM109 cells to generate BLV-LTR/Luc reporter gene expressing cells.

\subsection{Transfections and luciferase assays}

Human embryonic kidney $293 \mathrm{~T}$ cells, fetal lamb kidney (FLK) and BLV-infected FLK (FLK-BLV) cells were transfected during the log phase of their growth by lipofection with plasmid DNA prepared and purified using the QIAGEN plasmid Midi kit (QIAGEN, Maryland, USA). Following incubation with $0.5 \mu \mathrm{g}$ of construct DNA plus $25 \mathrm{ng}$ of pRL-TK control plasmid encoding Renilla reniformis luciferase (Promega) as control for transfection efficiency, cells were transfected using Lipofectamine $^{\mathrm{TM}} 2000$ (Invitorogen, Carlsbad, CA, USA) for 293T and FLK-BLV cells or FuGENE ${ }^{\mathrm{TM}} 6$ (Roche Diagnostics) for FLK. Additionally, to determine whether BLV-Tax could influence transcriptional trans-activation, FLK cells were co-transfected with $0.5 \mu \mathrm{g}$ of a Tax-expressing plasmid (pME-Tax, kindly donated by Dr. Yoko Aida and Dr. Shigeru Tajima, Institute of Physical and Chemical Research (RIKEN), Wako, Japan) or the control plasmid (pME18Neo) as described previously [19]. Twenty-four hours after transfection, cells were harvested and their lysates assayed using Dual-Luciferase Reporter Assay System (Promega) as described by the 
manufacturer. The luciferase activities of triplicate cultures were determined using a Luminescencer-JNR AB2010 (ATTO bio-instrument, Tokyo, Japan). For each sample, the firefly luciferase activity (pGL3 vector) was normalized by reference to Renilla luciferase activity (pRL-TK). The extent of trans-activation (-fold) was calculated by dividing the trans-activation activity of each plasmid by that of the cell lysate transfected with the control plasmid. Data were analyzed by one-way analysis of variance followed by Student t-test. Differences between groups were considered significant if probability values of $\mathrm{p}<0.05$ were obtained

\subsection{Quantification of TNF-a mRNA}

Total RNA was extracted from freshly isolated or cultivated PBMCs (peripheral blood mononuclear cells) by using the $\mathrm{TRIZOL}^{\mathrm{TM}}$ reagent according to the manufacturer's protocol (Invitrogen). All samples were treated with deoxyribonuclease I (amplification grade, Invitrogen) to eliminate DNA contamination. cDNA was synthesized with the Transcriptor 1st Strand cDNA Synthesis kit (Roche Diagnostics) according to the manufacture's instructions. Real-time RT-PCR using SYBER Green I was performed using a LightCycler ${ }^{\mathrm{TM}}$ (Roche Diagnostics) as described previously [13]. The cDNA template was added to a total volume of $20 \mu$ l containing PCR buffer, oligonucleotide primers (at $0.2 \mu \mathrm{M}$ each of TNF- $\alpha$ sense: 5'-TAA CAA GCC GGT AGC CCA CG-3' and TNF- $\alpha$ anti-sense: 5'-GCA AGG GCT CTT GAT GGC AGA-3') [20], and $2 \mu 1$ of LightCycler-Fast Start DNA Master SYBER Green I (Roche Diagnostics). The bovine $\beta$-actin gene in each sample was also amplified 
using primer pair $\beta$-actin sense (5'-CGC ACC ACT GGC ATT GTC AT-3') and $\beta$-actin anti-sense (5'-TCC AAG GCG ACG TAG CAG AG-3') to check for loading of template cDNAs. The relative mRNA values were worked out as ratios by dividing the concentration of the PCR product from the TNF- $\alpha$ cDNA by that from the $\beta$-actin cDNA. Data were analyzed by one-way analysis of variance followed by Student t-test. Differences between groups were considered significant if probability values of $\mathrm{p}<0.05$ were obtained.

\section{RESULTS}

3.1 Association of $-824 A / G$ polymorphism of TNF-a promoter with BLV disease progression in cattle

There were no significant differences in the frequency of TNF- $\alpha$ alleles between BLV-positive and -negative controls (Table 1). The frequencies of TNF- $\alpha$ alleles in BLV-infected cattle, AL, PL and lymphoma are shown in Table 2. Regarding the frequencies of the $-793 \mathrm{C} / \mathrm{T}$ and the $-627 \mathrm{C} / \mathrm{G}$ alleles, $\mathrm{BLV}$-infected but healthy cattle without lymphoma and cattle with lymphoma showed similar distribution. In contrast, the distribution of the $-824 \mathrm{~A} / \mathrm{G}$ genotype was significantly different between cattle with lymphoma and the BLV-infected but healthy cattle $\left(\chi^{2}=8.964, p=0.011\right)$. The difference was due to the increased frequency of the $-824 \mathrm{G} / \mathrm{G}$ homozygote alleles in lymphoma-positive cattle $\left(\chi^{2}=8.31312, p u=0.00394, p c=0.01181\right) . \quad$ In addition, there was a notable difference in the frequency of the $-824 \mathrm{~A} / \mathrm{G}$ genotype between cattle with lymphoma and with $\operatorname{AL}\left(\chi^{2}=6.293, p=0.043\right)$. The difference was attributed to an 
increase in the frequency of the $\mathrm{G} / \mathrm{G}$ homozygote allele $\left(\chi^{2}=6.244, p u=0.0129\right.$, $p c=0.0386$ ) with a concomitant decrease in the frequency of the $-824 \mathrm{~A} / \mathrm{G}$ heterozygote allele $\left(\chi^{2}=4.187, p u=0.0363, p c=0.1089\right)$ in lymphoma-positive cattle. There were no observable significant differences in the polymorphism of the $-824 \mathrm{~A} / \mathrm{G}$ allele among the three BLV-infected groups of cattle (except between lymphoma-positive and AL cattle)

Regarding the frequencies of the $\mathrm{C} / \mathrm{T}$ genotype at the $R s a \mathrm{I}$ restriction site in exon 4 , BLV-infected cattle without lymphoma and cattle with lymphoma also showed similar distribution, although statistically significant differences were found in the distribution of the genotype between lymphoma-positive and AL cattle. In addition, the RsaI C/T polymorphism did not result into amino acid substitution. Thus, this appears not to be associated with disease progression.

\subsection{Polymorphism in TNF-a promoter region and the provirus load}

To further evaluate the association of the $-824 \mathrm{~A} / \mathrm{G}$ polymorphism of TNF- $\alpha$ promoter with the viral propagation rate in BLV-infected individuals, the provirus loads were determined in 107 BLV-infected cattle without any clinical evidence of lymphoma by real-time PCR system. There were no significant differences in the provirus load between the $-824 \mathrm{~A} / \mathrm{A}$ homozygote and the $-824 \mathrm{~A} / \mathrm{G}$ heterozygote cattle. In contrast, the provirus load was significantly increased in cattle with $-824 \mathrm{G} / \mathrm{G}$ homozygote allele $(17.3 \pm 13.5 \%)$ compared to cattle with $-824 \mathrm{~A} / \mathrm{G}$ heterozygote allele $(10.9 \pm 11.3 \%$, $p=0.021$ ) (Fig. 1). Cattle with the $-824 \mathrm{G} / \mathrm{G}$ allele had a higher mean provirus load compared with the $-824 \mathrm{~A} / \mathrm{A}$ homozygote cattle, although the difference was not 
statistically significant $(10.3 \pm 9.3 \%, p=0.065)$. This would imply that the $-824 \mathrm{~A} / \mathrm{G}$ polymorphism of TNF- $\alpha$ promoter could influence the expression of TNF- $\alpha$ and subsequently necessitate the elimination of BLV in the course of infection. To check this possibility, we examined whether there was down-regulation of the expression of TNF- $\alpha$ in BLV-infected cattle bearing the $-824 \mathrm{G} / \mathrm{G}$ homozygote allele by determining the level of TNF- $\alpha$ mRNA in freshly isolated PBMCs by real-time PCR system. However, in contrast to the previous experimental study in sheep [6], TNF- $\alpha$ mRNA levels were found to be low or undetectable in cattle naturally infected with BLV and bearing the $-824 \mathrm{~A} / \mathrm{G}$ heterozygote, $-824 \mathrm{~A} / \mathrm{A}$ homozygote or $-824 \mathrm{G} / \mathrm{G}$ homozygote alleles (data not shown).

\subsection{Transcriptional promoter activity of the TNF-a gene}

We performed the luciferase assay to assess whether $T N F-a-824 \mathrm{~A} / \mathrm{G}$ influences the transcriptional promoter activity of the TNF- $\alpha$ gene (Fig. 2B, C and D). In 293T cells, the $-824 \mathrm{~A}$ promoter showed significantly higher luciferase activity than the $-824 \mathrm{G}$ promoter in the cells $(4.70 \pm 0.46$ vs $3.09 \pm 0.43$; p < 0.02) (Fig 2B). Similarly, the mean transcriptional promoter activities were significantly increased in -824A promoter compared to $-824 \mathrm{G}$ promoter in FLK-cells $(6.07 \pm 0.14$ vs $2.34 \pm 0.08 ; \mathrm{p}<0.001$, Fig $2 \mathrm{C})$ and FLK-BLV cells $(9.28 \pm 0.41$ vs $2.25 \pm 0.65 ; \mathrm{P}<0.001$, Fig. 2D). The BLV-Tax proteins were identified originally as factors that activated transcription from the respective BLV-LTR. In addition to its role in the activation of the viral enhancer, the Tax proteins of HTLV-1 and BLV modulates the expression of a variety of cellular 
genes that are related to the regulation of cell growth, via interaction with distinct promoter/enhancer sequences. To check this possibility, we examined if the transcriptional promoter activity of the TNF- $\alpha$ gene could be influenced by BLV-Tax. However, no detectable modification of the transactivation was observed between -824A promoter and -824G promoter in BLV-negative FLK cells expressing BLV-Tax, whereas the BLV-Tax strongly transactivated the plasmid pGL3-BLV-LTR/Luc which contains a viral promoter. We could not, however, confirm the up-regulation of transactivation in BLV-infected cells (FLK-BLV cells), although the transcriptional promoter activity was significantly higher in the $-824 \mathrm{~A}$ allele than in the $-824 \mathrm{G}$ allele.

3.4 TNF-a expression in PBMCs derived from cattle with different promoter polymorphism

In order to investigate the differences in the expression levels of the TNF- $\alpha$ in cattle with different promoter polymorphism, we used real-time PCR to quantify the expression of TNF- $\alpha$ mRNAs in concanavalin A-stimulated PBMC isolated from normal cattle (Fig. 3). A limited number of cattle were tested (2 Japanese black and 2 Holstein-Friesian), yet as expected, the degree of TNF- $\alpha$ mRNA expression was notably higher in cattle with the $-824 \mathrm{~A} / \mathrm{G}$ heterozygote allele than in cattle with the $-824 \mathrm{G} / \mathrm{G}$ homozygote allele. Un-stimulated PBMCs did not show any differences in the TNF- $\alpha$ expression levels among cattle (data not shown). Thus, these results suggest that $T N F-a-824 \mathrm{~A} / \mathrm{G}$ allele could influence the expression level of TNF- $\alpha$ and subsequent elimination of BLV. However, the results need to be confirmed using a 
larger sample size of cattle carrying different alleles and including BLV-infected cattle.

\section{DISCUSSION}

TNF- $\alpha$ is involved in host defense and is a protective factor against the progression of various viral infections [4,5]. In BLV-infected animals, a good correlation was observed between up-regulation of TNF- $\alpha$ and BLV clearance or resistance to disease progression but with notable individual variations [6]. We had hypothesized that the differences in expression levels of TNF- $\alpha$ brought about by the different genetic backgrounds of individuals could be responsible for the differences in TNF-induced responses to BLV infection among different individuals. In the present study, to evaluate this possibility, we investigated the polymorphisms in the 5'-flanking region of the TNF- $\alpha$ gene during the different stages of BLV infection, and found that the frequency of the TNF- $\alpha-824 \mathrm{G}$ allele, which has been associated with high proviral loads, was higher in individuals with BLV-induced lymphoma than in healthy carriers or normal controls. We also observed higher luciferase activity and increased concanavalin-A stimulated TNF- $\alpha$ mRNA expression in TNF- $\alpha-824 \mathrm{~A}$ allele than in the TNF- $\alpha-824 G$ allele.

Although the role played by the TNF- $\alpha$ promoter region $-824 \mathrm{~A} / \mathrm{G}$ polymorphism in tumorigenesis of the BLV-induced lymphoma is still speculative, our findings underscore earlier reports associating polymorphisms in the TNF- $\alpha$ promoter/enhancer region and disease progression in human (Fig 4). In the case of HTLV-I infection, the association of provirus load and TNF- $\alpha$ promoter polymorphism at position -1031 and 
-863 has been reported in HTLV-I associated uveitis (HU) patients [9]. Nishimura et al [10] found that the distribution of the $-857 \mathrm{~T} / \mathrm{C}$ genotype was significantly different between HTLV-I-associated myelopathy (HAM) patients and sero-negative controls. In addition, Tukasaki et al [11] found that the frequency of the TNF- $\alpha-857 \mathrm{~T}$ allele, reported to be associated with high transcriptional activity of the promoter/enhancer region of the TNF- $\alpha$ gene, was increased in individuals with T-cell leukemia/lymphoma (ATL) compared with healthy carriers. These observations point to the idea that TNF- $\alpha$ gene expression levels are associated with the polymorphisms in its promoter sequence. Indeed, Higuchi et al [22] reported that the transcriptional promoter activities of the $-1031 \mathrm{C},-863 \mathrm{~A}$ and $-857 \mathrm{~T}$ TNF- $\alpha$ promoter alleles in response to concanavalin A stimulation of PBMCs (as revealed by luciferase assay), were higher than those of the dominant alleles in human. In these polymorphisms in the TNF- $\alpha$ promoter, a number of studies have indicated that the polymorphisms in the promoter region change the binding of various nuclear factors that up- or down-regulate transcription. Interestingly, Heel et al [23] demonstrated that the transcription factor OCT-1 binds the TNF-857T of the TNFP-D allele, but not the $-857 \mathrm{C}$ of the TNFP-A, B and $\mathrm{C}$ alleles and interacts in vitro and in vivo with the proinflammatory NF-кB transcription factor p65 subunit at the adjacent binding site, $-863 \mathrm{C} / \mathrm{A}$. Therefore, it seems likely that these polymorphisms in the TNF- $\alpha$ promoter could influence to susceptibility to several infectious diseases in human. Although, the roles of the polymorphisms of the bovine TNF- $\alpha$ gene have not been reported, we postulated that the $-824 \mathrm{~A} / \mathrm{G}$ polymorphism might be associated with expression of TNF- $\alpha$ for 
BLV-elimination. To check this possibility, the RNA transcripts of TNF- $\alpha$ gene in fresh PBMCs were analyzed among BLV-infected cattle with different TNF- $\alpha$ genotypes. However, no detectable expression of TNF- $\alpha$ was observed in fresh PBMC (data not shown). In addition, although the mean TNF- $\alpha$ protein levels were higher in BLV-infected cattle than the control cattle as described previously [24], the difference between the two groups was not statistically significant. There were also no significant differences among cattle with different TNF- $\alpha$ genotypes (data not shown). The importance of TNF- $\alpha$ for the antiviral response and for tumor promotion is well established. In particular, Mullar and co-workers [8], using a TNF- $\alpha-/-$ mice model, have shown that the ability of the host to mount a TNF- $\alpha$ response is crucial in the host's immune defense system during the first phase of BLV infection. These data, although not showing statistically significant difference between the test group and the controls, might suggest that TNF- $\alpha$ has a defense function in the early phase of BLV infection. Further elucidation of the differences in TNF- $\alpha$ production in relation to the $\mathrm{TNF}-\alpha-824 \mathrm{~A} / \mathrm{G}$ polymorphisms is inevitable.

On the other hand, we had previously reported contrasting roles played by TNF- $\alpha$ in the pathogenesis of BLV-infection in the early phase of infection. In the late phase of the infection, B-cell derived TNF- $\alpha$ was shown to strongly induce the proliferative response of B-cells upon binding to the specific receptors, TNF-RI and TNF-RII. Further, the susceptibility to viral infection and development of the BLV-infection was shown to be determined by TNF-induced responses and linked to the binding of TNF- $\alpha$ to its receptors [7,13,24]. In HTLV-I infection, aberrant production of several 
cytokines and their receptors was thought to be a result of the transactivating ability of the Tax protein of HTLV-I. Although the role played by the BLV Tax is unknown, it has, nevertheless, been shown to enhance nuclear protooncogene such as c-fos [19]. In this report, we showed that polymorphisms in the TNF- $\alpha$ promoter, $-824 \mathrm{G}$ are associated with the BLV-induced lymphoma and elevation of provirus load in BLV-infected individuals. These observations raise the possibility that the polymorphism in promoter region of TNF- $\alpha$ gene might be influenced by transactivation through the BLV regulatory gene product, Tax. To check this possibility, the transactivation of both TNF- $\alpha-824 \mathrm{G}$ and TNF- $\alpha-824 \mathrm{~A}$ was analyzed in BLV-Tax expressing cell. However, no detectable modification of the transactivation was observed in BLV-negative FLK cells expressing BLV-Tax. In addition, we could not confirm the up-regulation differences of transactivation between TNF- $\alpha-824 \mathrm{G}$ and TNF- $\alpha-824 \mathrm{~A}$ in BLV-infected cells. At present, the TNF- $\alpha-824 \mathrm{~A} / \mathrm{G}$ polymorphism in promoter region of TNF- $\alpha$ gene can not, at least in part, be attributed to the up-regulation of transactivation of TNF- $\alpha$ via BLV-Tax. Although the aberrant production of TNF- $\alpha$ plays a central role in the disease pathogenesis in the late phase of the BLV-infection, the response may be induced by other mechanisms such as TNF- $\alpha$ overexpression via BLV-Tax-induced inhibition of tristetraprolin (TTI) [25].

Both genetic and immunological factors contribute to susceptibility to BLV-induced disease progressions $[3,26]$. In genetic analysis of BLV-infection, previous studies revealed the polymorphism in bovine leukocyte antigen (BoLA)-DR $\beta$ chain associated with resistance to expansion of BLV [27] and PL [28]. Furthermore, it appeared that 
ovine leukocyte antigen (Ovar)-DRB1 alleles encoding the RK motif at positions 70-71 of the Ovar-DR $\beta$ chain might protect against tumor development after experimental infection of sheep with BLV [29], and sheep with alleles encoding the RK motif could induce cellular immunity [30]. In this report, we showed that polymorphisms in the TNF- $\alpha$ promoter, $-824 \mathrm{G}$, which indicated low transcriptional activity, is associated with the BLV-induced lymphoma and elevation of provirus load in BLV-infected individuals. To our knowledge, this is one of the first reports showing a cytokine genetic polymorphism associated with the susceptibility to development of lymphoma among BLV-infected cattle. To date, several cytokines such as interleukin (IL)-2, IL-4, IL-10, IL-12, interferon (IFN)- $\gamma$, IL-2 receptor and TNF- $\alpha$ and their receptors have been reported to be associated with disease progression in BLV-infection, $[3,6-8,13,15,24,25,30]$. However, it seems likely that it is easy to see individual variabilities among animals in these responses. Indeed, although we showed the importance of TNF-receptor balance in BLV-induced disease progression, we also observed individual variabilities among the results. Because we used cattle naturally infected with BLV, it was quite difficult to get same results as would be expected in experimental infections. One possibility for the apparent lack of penetrance in individual animals is genetic background resulting in the resistance or susceptibility to disease progression. Indeed, the association between TNF-receptor II gene polymorphism and the susceptibility to HTLV-I-induced HAM has also been reported in humans [10]. However, a direct linkage between cytokines and their receptors' genetic polymorphisms including TNF- $\alpha$ and the susceptibility to disease has not been 
identified in domestic animals. These studies could contribute to breeding strategies aimed at improving resistance to infectious diseases. Therefore, alterations in the biological nature and physiological function of the cytokine and the receptor genetic polymorphisms in BLV-induced lymphoma, in association with resistance or susceptibility to tumor development, are also worthy of further examination.

\section{Acknowledgment}

The encyclopedic BLV and TNF knowledge of Dr. Hidenori Kabeya is gratefully appreciated. We are indebted to Dr. Yoko Aida and Dr. Shigeru Tajima, RIKEN Institute, for donating the plasmids, and Dr. Witola William Harold for the help in preparing the manuscript. This work was supported by grants-in-Aid for Scientific Research from the Japan Society for the Promotion of Science (JSPS), and by a special grant for the promotion of research from the Japanese Society for Animal Cytokine Research (JSACR).

\section{References}

[1] N. Sagata, T. Yasunaga, J. Tsuzuku-Kawamura, K. Ohishi, Y. Ogawa, Y. Ikawa, Complete nucleotide sequence of the genome of bovine leukemia virus: its evolutionary relationship to other retroviruses. Proc. Natl. Acad. Sci. USA 82 (1985) 677-681.

[2] M.L. Mirsky, C.A. Olmstead, Y. Da, H.A. Lewin, The prevalence of proviral bovine leukemia virus in peripheral blood mononuclear cells at two subclinical 
stages of infection. J. Virol. 70 (1996) 2178-2183.

[3] H. Kabeya, K. Ohashi, M. Onuma, Host immune responses in the course of bovine leukemia virus infection. J. Vet. Med. Sci. 61 (2001) 475-480.

[4] L.G. Guidotti, F.V. Chisari, Cytokine-mediated control of viral infections. Virology 273 (2000) 221-227.

[5] G. Herbein, W.A. O'Brien, Tumor necrosis factor (TNF)-alpha and TNF receptors in viral pathogenesis. Proc. Soc. Exp. Biol. Med. 223 (2000) 241-257.

[6] H. Kabeya, K. Ohashi, N. Oyunbileg, Y. Nagaoka, Y. Aida, C. Sugimoto, Y. Yokomizo, M. Onuma, Up-regulation of tumor necrosis factor alpha mRNA is associated with bovine-leukemia virus (BLV) elimination in the early phase of infection. Vet. Immunol. Immunopathol. 68 (1999) 255-265.

[7] H. Kabeya, A. Fukuda, K. Ohashi, C. Sugimoto, M. Onuma, Tumor necrosis factor alpha and its receptors in experimentally bovine leukemia virus-infected sheep. Vet. Immunol. Immunopathol. 81 (2001) 129-139.

[8] C. Mullar, T.J. Coffey, M. Koss, J.P. Teifke, W. Langhans, D. Werling, Lack of TNF alpha supports persistence of a plasmid encoding the bovine leukemia virus in TNF-/- mice. Vet. Immunol. Immunopathol. 92 (2003) 15-22.

[9] N. Seki, K. Yamaguchi, A. Yamada, S. Kamizono, S. Sugita, C. Taguchi, M. Matsuoka, H. Matsumoto, S. Nishizaka, K. Itoh, M. Mochizuki, Polymorphism of the 5'-flanking region of the tumor necrosis factor (TNF)-alpha gene and susceptibility to human T-cell lymphotropic virus type I (HTLV-I) uveitis. J. Infect. Dis. 180 (1999) 880-883. 
[10] M. Nishimura, M. Maeda, M. Matsuoka, H. Mine, H. Saji, M. Matsui, Y. Kuroda, H. Kawakami, T. Uchiyama, Tumor necrosis factor, tumor necrosis factor receptors type 1 and 2, lymphotoxin-alpha, and HLA-DRB1 gene polymorphisms in human T-cell lymphotropic virus type I associated myelopathy. Hum. Immunol. 61 (2000) 1262-1269.

[11] K. Tsukasaki, C.W. Miller, T. Kubota, S. Takeuchi, T. Fujimoto, S. Ikeda, T.M. Tomonaga, H.P. Koeffler, Tumor necrosis factor alpha polymorphism associated with increased susceptibility to development of adult T-cell leukemia/lymphoma in human T-lymphotropic virus type 1 carriers. Cancer Res. 61 (2001) $3770-3774$.

[12] M. Nishimura, M. Maeda, J. Yasunaga, H. Kawakami, R. Kaji, A. Adachi, T. Uchiyama, M. Matsuoka, Influence of cytokine and mannose binding protein gene polymorphisms on human T-cell leukemia virus type I (hTLV-I) provirus load in HTLV-I asymptomatic carriers. Hum. Immunol. 64 (2003) 453-457.

[13] S. Konnai, T. Usui, M. Ikeda, J. Kohara, T. Hirata, K. Okada, K. Ohashi, M. Onuma, Imbalance of tumor necrosis factor receptors during progression in bovine leukemia virus infection. Virology 339 (2005) 239-248.

[14] S. Tajima, M. Takahashi, S. Takeshima, S. Konnai, S.A. Yin, S. Watarai, Y. Tanaka, M. Onuma, K. Okada, Y. Aida, A mutant form of the tax protein of bovine leukemia virus (BLV), with enhanced transactivation activity, increases expression and propagation of BLV in vitro but not in vivo. J. Virol. 77 (2003) 1894-1903. 
[15] M. Ikeda, S. Konnai, M. Onuma, N. Ishiguro, M Goryo, K. Okada, Immunohistochemical analysis of expression patterns of tumor necrosis factor receptors on lymphoma cells in enzootic bovine leukosis. J. Vet. Med. Sci. 67 (2005) 425-432.

[16] W.M. Grosse, S.M. Kappes, W.W. Laegreid, J.W. Keele, C.G. Chitko-McKown, M.P. Heaton, Single nucleotide polymorphism (SNP) discovery and linkage mapping of bovine cytokine genes. Mamm. Genome 10 (1999) 1062-1069.

[17] I. Cludts, Y. Cleuter, R. Kettmann, A. Burny, L. Droogmans, Cloning and characterization of the tandemly arranged bovine lymphotoxin and tumor necrosis factor-alpha genes. Cytokine 5 (1993) 336-341.

[18] M. Higuchi, N. Miyashita, T. Awata, A PCR-RFLP in the cording region of the bovine tumor necrosis factor-a locus. J. Anim. Sci. 77 (1999) 3400-3401.

[19] S. Tajima, Y. Aida, Mutant tax protein from bovine leukemia virus with enhanced ability to activate the expression of c-fos. J. Virol. 76 (2002) $2557-2562$.

[20] T.P. Neuvians, D. Schams, B. Berisha, M.W. Pfaffl, Involvement of pro-inflammatory cytokines, mediators of inflammation, and basic fibroblast growth factor in prostaglandin F2alpha-induced luteolysis in bovine corpus luteum. Biol. Reprod. 70 (2004) 473-480.

[21] S.A, Nedospasov, A.N. Shakhov, R.L. Turetskaya, V.A. Mett, M.M. Azizov, G.P. Georgiev, V.G. Korobko, V.N. Dobrynin, S.A. Filippov, N.S. Bystrov, Tandem arrangement of genes coding for tumor necrosis factor (TNF-alpha) and 
lymphotoxin (TNF-beta) in the human genome. Cold Spring Harb. Symp. Quant. Biol. 51 (1986) 611-624.

[22] T. Higuchi, N. Seki, S. Kamizono, A. Yamada, A. Kimura, H. Kato, K. Itoh, Polymorphism of the 5'-flanking region of tumor necrosis factor (TNF)- $\alpha$ gene in Japanese. Tissue antigen 51 (1998) 605-612.

[23] D.A. van Heel, I.A. Udalova, A.P. De Silva, D.P. McGovern, Y. Kinouchi, J. Hull, N.J. Lench, L.R. Cardon, A.H. Carey, D.P. Jewell, D. Kwiatkowski, Inflammatory bowel disease is associated with a TNF polymorphism that affects an interaction between the OCT-1 and $\mathrm{NF}(-\kappa) \mathrm{B}$ transcription factors. Hum. Mol. Genetics 11 (2002) 1281-1289.

[24] S. Konnai, T. Usui, M. Ikeda, J. Kohara, T. Hirata, K. Okada, K. Ohashi, M. Onuma, Tumor necrosis factor-alpha up-regulation in spontaneously proliferating cells derived from bovine leukemia virus-infected cattle. Arch. Virol. 151 (2006) 347-360.

[25] J.C. Twizere, V. Kruys, L. Lefebvre, A. Vanderplasschen, D. Collete, C. Debacq, W.S. Lai, J.C. Jauniaux, L.R. Bernstein, O.J. Semmes, A. Burny, P.J. Blackshear, R. Kettmann, L. Willems, Interaction of retroviral Tax oncoproteins with tristetraprolin and regulation of tumor necrosis factor-alpha expression. J. Natl. Cancer Inst. 95 (2003) 1846-1859.

[26] H.A. Lewin, G.C. Russell, E.J. Glass, Comparative organization and function of the major histocompatibility complex of domesticated cattle. Immunol. Rev. 167 (1999) 145-158. 
[27] M.L. Mirsky, C. Olmstead, Y. Da, H.A. Lewin, Reduced bovine leukemia virus proviral load in genetically resistant cattle. Anim. Genet. 29 (1998) 245-252.

[28] A. Xu, M.J. van Eijk, C. Park, H.A. Lewin, Polymorphism in BoLA-DRB3 exon 2 correlates with resistance to persistent lymphocytosis caused by bovine leukemia virus. J. Immunol. 151 (1993) 6977-6985.

[29] Y. Nagaoka, H. Kabeya, M. Onuma, N. Kasai, K. Okada, Y. Aida, Ovine MHC class II DRB1 alleles associated with resistance or susceptibility to development of bovine leukemia virus-induced ovine lymphoma. Cancer Res. 59 (1999) 975-981.

[30] S. Konnai, S. Takeshima, S. Tajima, S.A. Yin, K. Okada, , M. Onuma, Y. Aida, The influence of ovine MHC class II DRB1 alleles on immune response in bovine leukemia virus infection. Microbiol. Immunol. 47 (2003) 223-232. 


\section{Figure legends}

Fig. 1. The provirus load in BLV-infected cattle with TNF- $\alpha-824 \mathrm{~A} / \mathrm{A}$ homozygote $(n=17), T N F-\alpha-824 A / G$ heterozygote $(n=62)$ and TNF- $\alpha-824 G / G$ homozygote $(n=28)$ alleles. The percentages of BLV-positive cells were determined from the quantification data obtained by real-time quantitative PCR. Cattle that were tested and found to be without lymphoma were 107 as depicted in Table 1. The dotted line indicates the mean percentage of BLV-infected cells in each group. Differences between groups were considered significant if probability values of $\mathrm{P}<0.05$ were obtained.

Fig. 2. Relationship between the TNF- $\alpha-824 \mathrm{~A} / \mathrm{G}$ polymorphism and transcriptional promoter activity. (A) Schematic representation of the reporter gene constructs used for transfection assays. (B) $293 \mathrm{~T}$ cells and (C) FLK cells were transfected with pGL3-TNF- $\alpha^{-824 \mathrm{~A}} /$ Luc or pGL3-TNF- $\alpha^{-824 \mathrm{G}} / \mathrm{Luc}$, and individual BLV-Tax-expressing plasmids (pME-Tax). (D) BLV-infected FLK cells were transfected with pGL3-TNF- $\alpha^{-824 \mathrm{~A}} /$ Luc or pGL3-TNF- $\alpha^{-824 \mathrm{G}} /$ Luc. For each sample, the firefly luciferase activity (pGL3) was normalized by reference to Renilla luciferase activity (pRL-TK). The values are means and standard deviations of results from three independent tranfections.

Fig. 3. Quantification of the expression of TNF- $\alpha$ mRNA in PBMCs by real-time PCR analysis. PBMCs from cattle with TNF- $\alpha-824 \mathrm{~A} / \mathrm{G}$ heterozygote (Pr.0423 and Pr. 
2924) or TNF- $\alpha-824 \mathrm{G} / \mathrm{G}$ homozygote (Pr.8012 and Pr.9446) were cultivated with concanavalin A $(5 \mu \mathrm{g} / \mathrm{ml})$ for 6 or 12 hours and harvested for RNA extraction. Bars represent the mean values of ratios obtained by dividing the concentrations of the PCR products from the TNF- $\alpha$ mRNAs by the dose from the $\beta$-actin mRNA. Average values from three wells with standard error are shown.

Fig. 4. Alignment of the nucleotide sequences of promoter/enhancer region of the human and bovine TNF- $\alpha$ gene and associated retroviral infections. The reference sequences have been reported by Jongeneel et al [21] (GenBank accession numbers: M16441) and Cludts et al [17] (Z14137). Numbers donate upstream positions from initiation of transcription site. The different nucleotides in the polymorphic sites are shown boxed and in boldface. TATA signals are indicated by a large box. Primer positions used for PCR amplification are underlined. TNF- $\alpha$ promoter polymorphism related to retroviral infections were cited from the reports by Seki et al [9], Tsukasaki et al [11] and Nishimura et al [10]. Data on different TNF- $\alpha$ expression levels in relation to TNF- $\alpha$ promoter polymorphism were taken from the report by Higuchi et al [22]. 


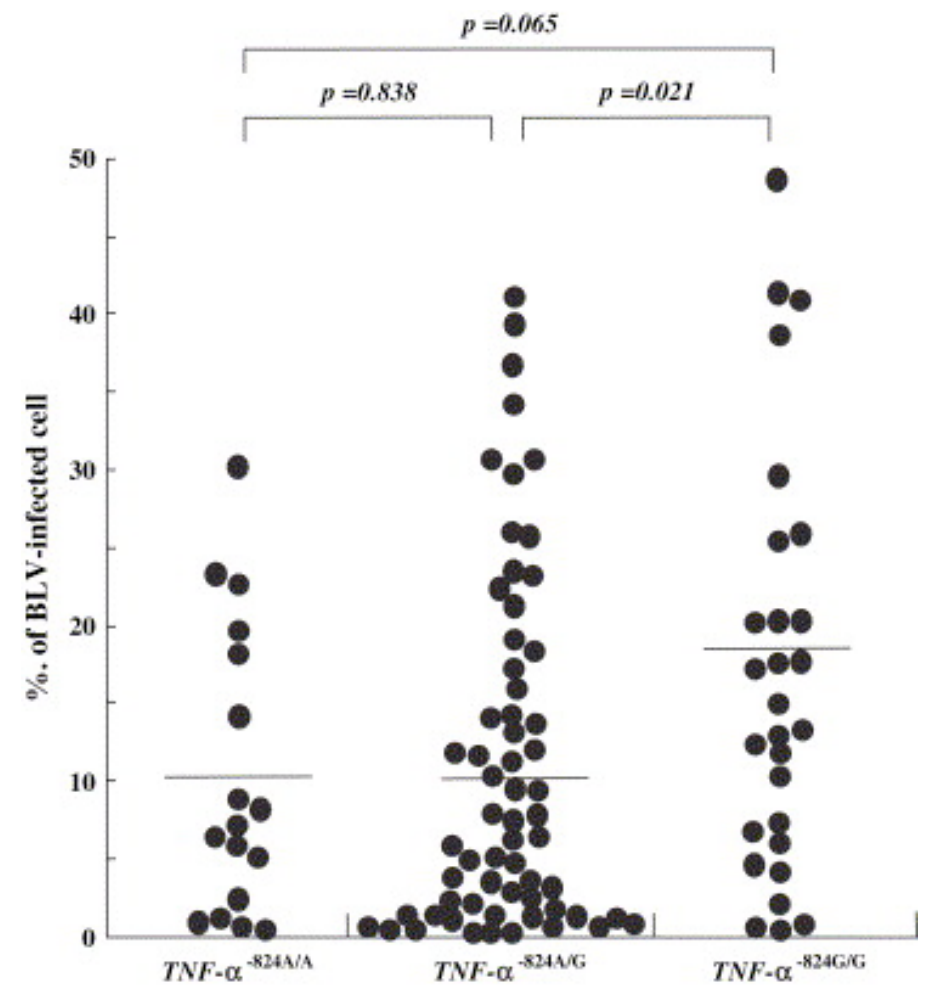

Fig. 1 
A

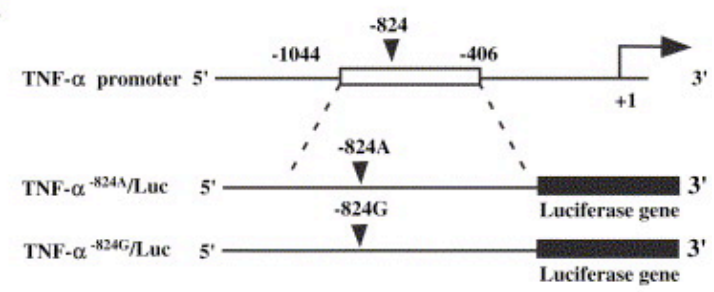

B

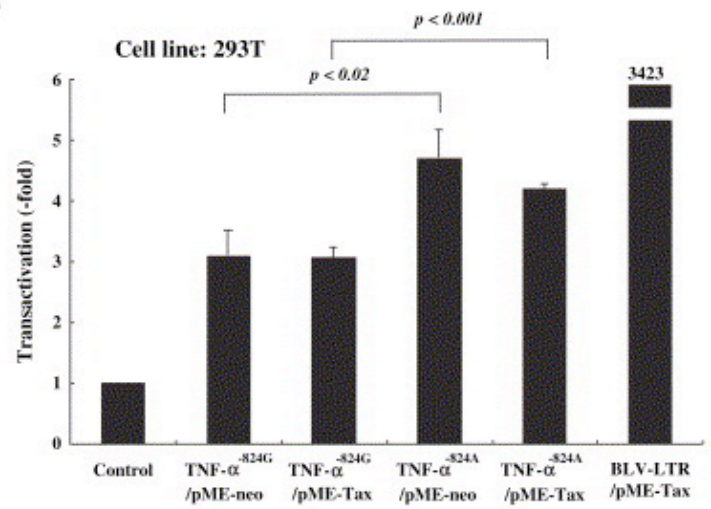

C

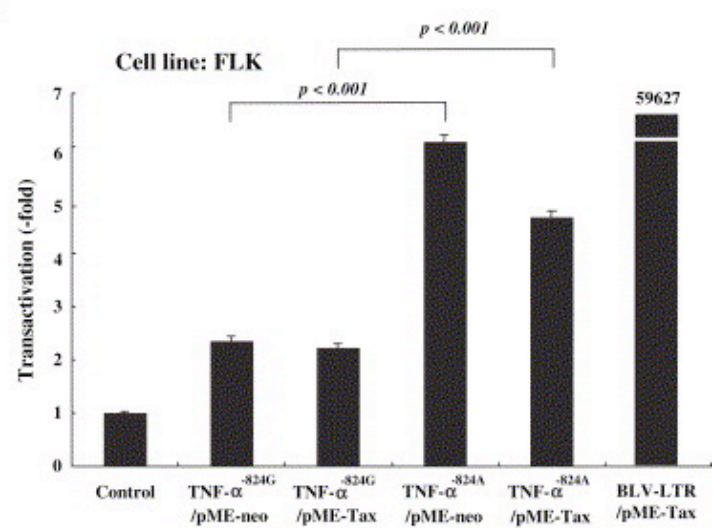

D

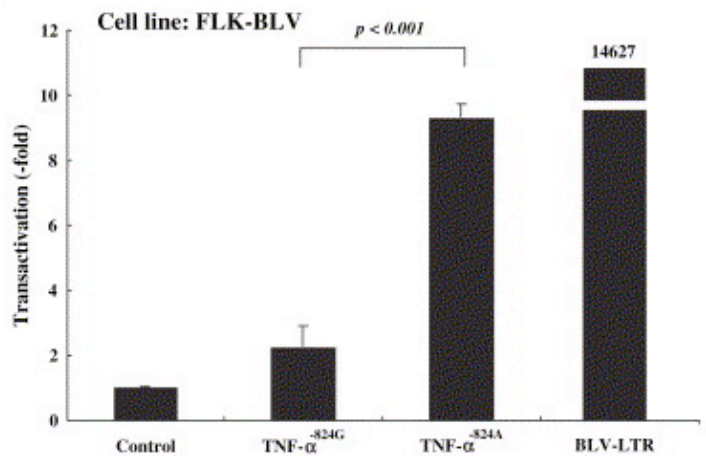

Fig. 2 


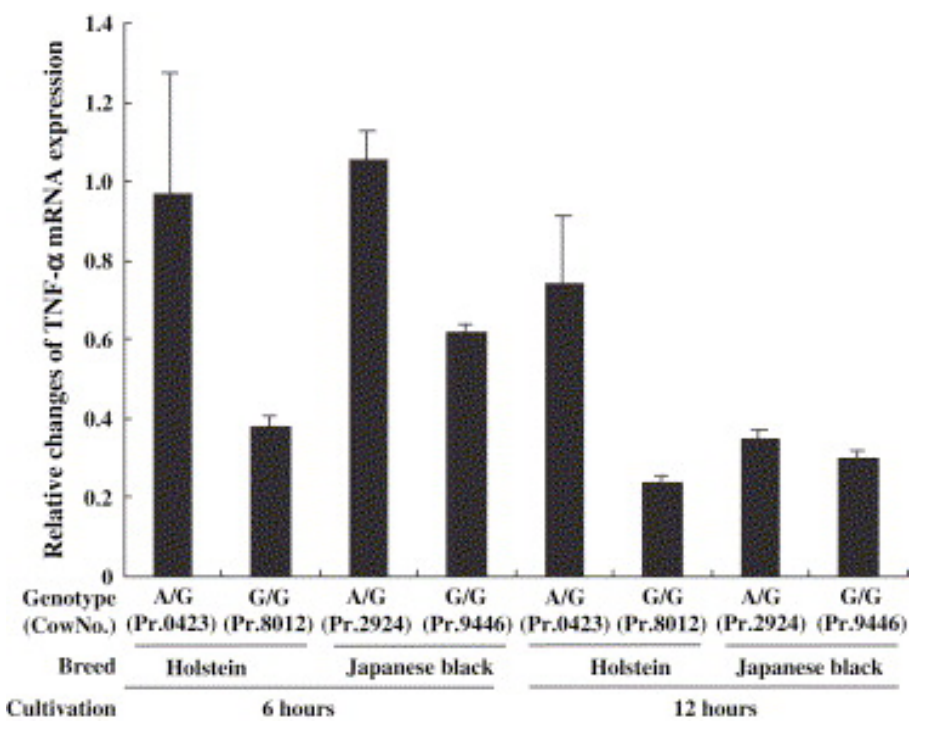

Fig. 3 


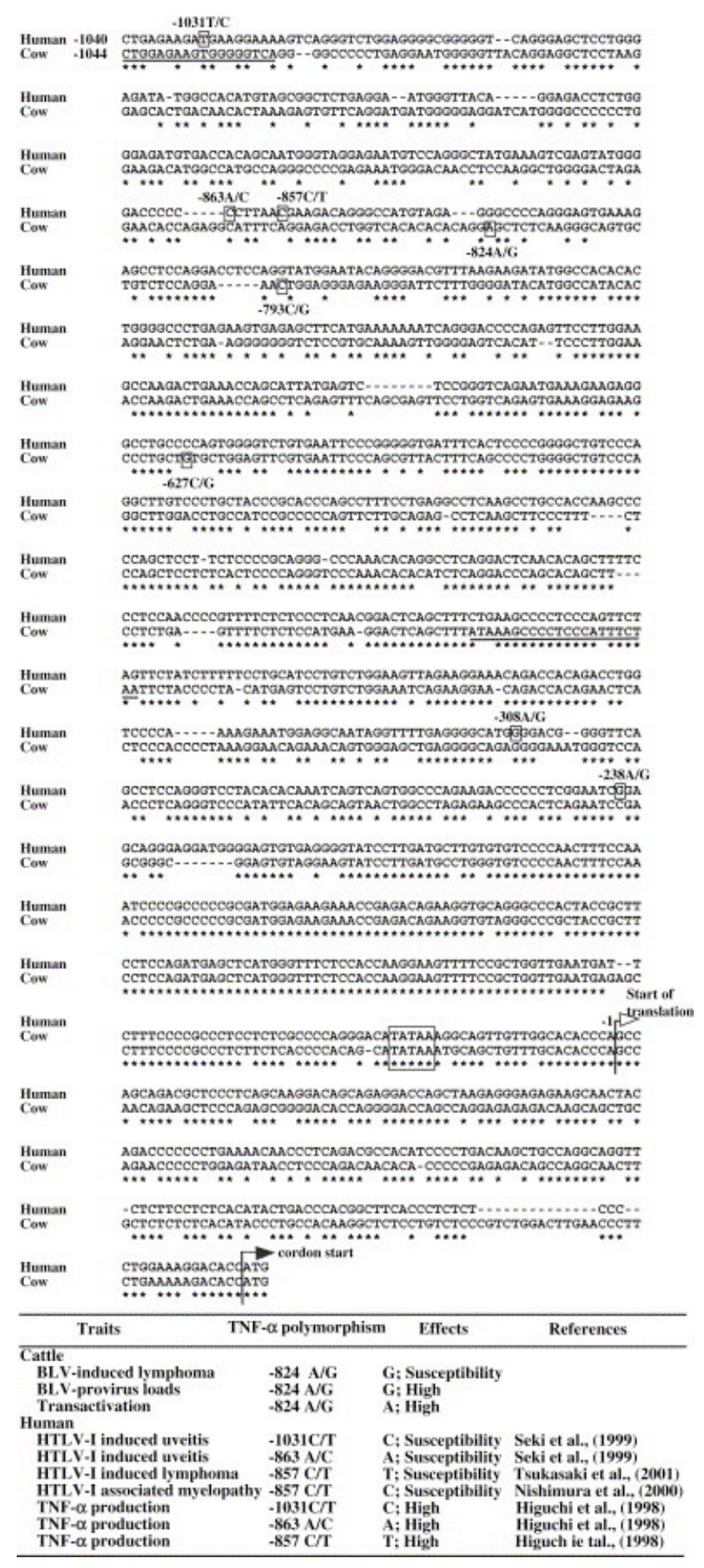

Fig. 4 